\title{
Neuropsychological and SPECT scan findings during and after transient global amnesia: evidence for the differential impairment of remote episodic memory
}

\author{
Jon Evans, Barbara Wilson, E Philip Wraight, John R Hodges
}

\begin{abstract}
A patient had neuropsychological testing during, and at two days and seven weeks after a transient global amnesia (TGA) attack. During the attack she exhibited a characteristically profound anterograde amnesia but a limited remote memory loss; the most striking impairment was a deficit in personal episodic memory revealed by her performance on the Autobiographical Memory Interview. Personal and general semantic information was less impaired although there were indications of a temporal gradient in the impairment. When tested after the attack, she demonstrated normal anterograde and retrograde memory. A SPECT scan performed during TGA showed a focal reduction in cerebral perfusion in the postero-medial temporal lobes bilaterally which had resolved after seven weeks.
\end{abstract}

$(\Im$ Neurol Neurosurg Psychiatry 1993;56:1227-1230)

The aetiology of transient global amnesia (TGA) remains unknown. The syndrome, first described by Bender ${ }^{1}$ and named by Fisher and Adams ${ }^{2}$ is characterised by a sudden onset of severe amnesia and confusion, often with repetitive questioning. According to strict diagnostic criteria, ${ }^{3}$ the onset of the attack should be witnessed (to exclude epilepsy or head injury as potential causes), and focal neurological features should be absent.

There are still only a small number of case studies in which neuropsychological testing has been carried out during and after TGA. ${ }^{4-12}$ Whilst dense anterograde amnesia is a defining characteristic of TGA, the extent and nature of any retrograde amnesia is much more variable. In the most detailed study to date, there was considerable heterogeneity amongst the five patients studied; whilst some patients had an extensive retrograde memory loss encompassing several decades, others had a very limited retrograde amnesia for the past few months only. ${ }^{9}$ There are a number of possible explanations for this variability. The simplest is that it reflects variation in the brain structures potentially affected during attacks; using SPECT, Stillhard et al ${ }^{10}$ and Tanabe et $a l^{12}$ found bilateral temporal lobe hypoperfusion during testing, whereas Goldenberg et $a l^{11}$ found reduction in regional blood flow in the left thalamus as well as more diffuse hypoperfusion of the cerebral cortex, including frontal areas. Information on cerebral blood flow and metabolism during TGA is, however, still very limited as these three cases $^{10-12}$ constitute the only reports of SPECT scanning during TGA.

Differing methods of assessing retrograde amnesia may also account for variation in reports of retrograde amnesia. Some studies have relied on informal questioning of patients about recent and past events. ${ }^{610}$ However, events from the past may, through frequent re-telling, take on the quality of semantic memories (memory for factual information or knowledge) rather than true episodic memories (memory for particular events which are specific in time and place)..$^{13}$ Hence informal questioning about significant personal and family events may not reveal an impairment in the ability to recall specific episodes. Questionnaires on personal and public events ${ }^{78}$ might also be answered with reference only to semantic knowledge. Some studies have utilised the 'Galton-Crovitz' test $^{7}{ }^{9}$ in which subjects are presented with a list of cue words and are required to describe an incident from their life which relates to the word, and then to date and place the memory. Although better at sampling true autobiographical episodes, the method has been criticised ${ }^{15}$ because the subject is not constrained to produce memories from specified time periods, making it difficult to draw any conclusions about temporal gradients in retrograde impairment.

We examined a patient during a TGA, then repeated assessments two days and seven weeks later. Short-term memory, orientation, anterograde and retrograde memory were assessed. SPECT scanning was also carried out during and after the attack.

\section{Case history}

The patient, a 55-year-old right-handed woman, had an uneventful past medical history. On the morning of the TGA episode she made herself breakfast and afterwards drove to her son's house. On arriving she was complaining of feeling muddled and was repeating the same questions. Her family 
contacted their medical practitioner and she was seen by us at Addenbrooke's Hospital about four hours after the onset of the attack. On admission, neurological examination was normal, she was oriented in person and place, but not in time. She had a severe anterograde amnesia and appeared, on informal questioning, unable to remember events from the previous month; she showed normal social interaction and was appropriately concerned about her condition. The episode lasted about 8-10 hours. A CT brain scan and EEG performed on the day after the attack were both normal.

\section{SPECT scanning}

Five hundred MBq of $99 \mathrm{mTc}-\mathrm{HMPAO}$ was injected intravenously after the patient had been resting quietly for 15 minutes. Tomographic images were acquired $15 \mathrm{~min}$ utes later using an IGE 400 AT tomographic camera with a high resolution colorimeter. Sixty four 20s images were acquired in a 64 $\times 64$ matrix over a 360 degree rotation. Transaxial, sagittal and coronal images were reconstructed by filtered back projection using a ramp Hanning filter without attenuation correction. SPECT scanning performed during the attack showed a marked focal reduction in perfusion in the postero-medial temporal lobes bilaterally. When repeated at seven weeks post-attack, the appearances had returned to normal (see fig). This assessment was qualitative. If quantitative methods had been used, additional deficits may have been shown.

\section{Neuropsychological testing}

During the attack, the Orientation, Digit Span and Visual Memory Span sub-tests from the Wechsler Memory Scale-Revised ${ }^{16}$ were used to assess orientation and shortterm memory. Anterograde memory was assessed by the Rivermead Behavioural Memory Test. ${ }^{17}$ Retrograde memory was investigated using the Autobiographical Memory Interview (AMI) ${ }^{18}$ which assesses both personal semantic knowledge (for example, the names of friends or teachers or colleagues, address of places lived, knowledge of educational and work history) and autobiographical episodic memory (details of specific episodes) across lifetime periods. A modified version of the Famous Faces Test and a Famous Events Test previously described in detail $^{9}$ were also administered. The Famous Faces Test consists of 50 faces of people who have been famous in different decades between 1940 and 1990. Subjects are requested to name the person; if they are unable to provide the name spontaneously, semantic and first name cues are provided. In the Famous Events Test, the subject has to distinguish 50 famous events from 50 distracter events, and then to date the events judged to be real. The National Adult Reading Test (NART) ${ }^{19}$ was used to estimate pre-morbid IQ. Two days later the Orientation, RBMT and AMI were repeated and 7 weeks later all the tests (apart from NART) were repeated. Different versions of the RBMT were used on each occasion to control for practice effects.

\section{Neuropsychological test results}

The scores obtained in the tests on the three occasions are presented in the table.

Orientation, working and anterograde memory The patient was estimated to have an average IQ pre-morbidly. She was disorientated in time (month, date, time) during TGA, but

Figure Above (sections 5 and 6): SPECT scan performed during TGA: adjacent transaxial sections $1.3 \mathrm{~cm}$ thick near the base of the brain showing reduced perfusion in the reduced perfusion in the lobes bilaterally (arrows). Below (sections 7 and 8): The same sections from the study 7 weeks after the episode of TGA showing that the defect has completely resolved.

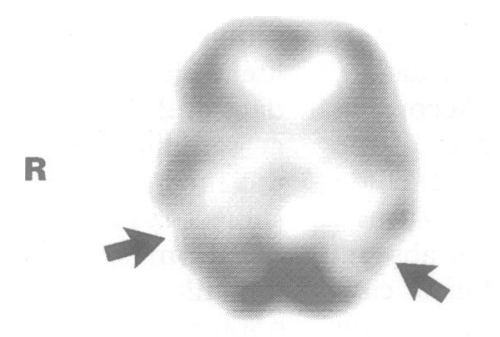

$\mathbf{L}$

$\mathbf{R}$

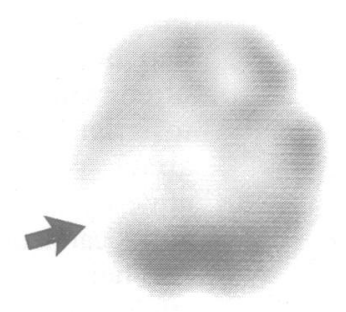

$\mathbf{L}$

5

6

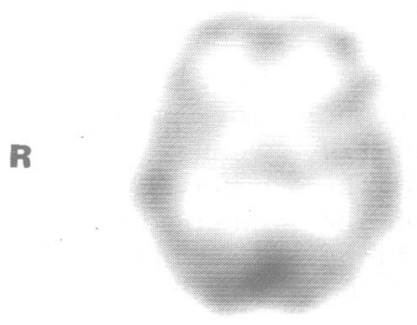


Table 1 Neuropsychological test results during and after $T G A$

\begin{tabular}{|c|c|c|c|}
\hline & During $T G A$ & 2 days post $T G A$ & 7 weeks post $T G A$ \\
\hline NART IQ & 98 & N/A & N/A \\
\hline $\begin{array}{r}\text { Digit span Forwards } \\
\text { Backwards }\end{array}$ & $\begin{array}{l}7 \\
4\end{array}$ & N/A & $\begin{array}{l}8 \\
3\end{array}$ \\
\hline $\begin{array}{r}\text { Visual memory span } \\
\text { Forwards } \\
\text { Backwards }\end{array}$ & $\begin{array}{l}6 \\
4\end{array}$ & N/A & $\begin{array}{l}4 \\
5\end{array}$ \\
\hline Orientation & $11 / 14$ & $14 / 14$ & $14 / 14$ \\
\hline $\begin{array}{l}\text { Rivermead Behavioural Memory Test } \\
\text { Standardised Profile Score }\end{array}$ & $2 / 24$ (severely impaired) & $22 / 24$ (normal) & $21 / 24$ (normal) \\
\hline $\begin{array}{l}\text { Autobiographical Memory Interview } \\
\text { Personal Semantic } \\
\text { Childhood } \\
\text { Early Adult Life } \\
\text { Recent Life }\end{array}$ & $\begin{array}{l}21 / 21 \text { (normal) } \\
20 \cdot 5 / 21 \text { (normal) } \\
14 / 21 \text { (abnormal) }\end{array}$ & $\begin{array}{l}21 / 21 \text { (normal) } \\
21 / 21 \text { (normal) } \\
21 / 21 \text { (normal) }\end{array}$ & $\begin{array}{l}21 / 21 \text { (normal) } \\
21 / 21 \text { (normal) } \\
21 / 21 \text { (normal) }\end{array}$ \\
\hline $\begin{array}{l}\text { Autobiographical incidents } \\
\text { Childhood } \\
\text { Early Adult Life } \\
\text { Recent Life }\end{array}$ & $\begin{array}{l}\text { 3/9 (abnormal) } \\
4 / 9 \text { (probably abnormal) } \\
2 / 9 \text { (abnormal) }\end{array}$ & $\begin{array}{l}7 / 9 \text { (normal) } \\
8 / 9 \text { (normal) } \\
9 / 9 \text { (normal) }\end{array}$ & $\begin{array}{l}7 / 9 \text { (normal) } \\
7 / 9 \text { (normal) } \\
9 / 9 \text { (normal) }\end{array}$ \\
\hline $\begin{array}{l}\text { Famous Faces } \\
\text { Named without cue } \\
\text { Named with semantic or phonemic cue }\end{array}$ & $\begin{array}{l}30 / 50 \\
17 / 20\end{array}$ & N/A & $\begin{array}{l}35 / 50 \\
13 / 15\end{array}$ \\
\hline $\begin{array}{l}\text { Famous Events } \\
\text { Famous events correctly recognised } \\
\text { Non-famous events identified as famous } \\
\text { (false positives) } \\
\text { Correctly dated for decade }\end{array}$ & $\begin{array}{l}36 / 50 \\
11 / 50\end{array}$ & N/A & $\begin{array}{l}35 / 50 \\
2 / 50\end{array}$ \\
\hline
\end{tabular}

N/A $=$ Not assessed

well oriented out of TGA. She showed unimpaired performance on tests of visual and verbal short-term memory. The initial RBMT score was indicative of a severe anterograde amnesia, whereas the scores two days and seven weeks later were in the normal range.

\section{Retrograde memory}

a) Autobiographical Memory Interview

In scoring the AMI, points are awarded for each item of semantic information and each autobiographical incident is rated on a $0-3$ scale of descriptive richness and specificity in time and place. Each autobiographical incident was rated by two raters and there was very good inter-rater agreement. During the attack, scores on the personal semantic information were within the normal range, apart from the recent life section, some of which ask for information about the current hospitalisation and therefore reflect, in this case, impairment in anterograde rather than retrograde memory. In contrast to relatively normal personal semantic information, thie patient's ability to describe detailed episodes in her life was impaired. Two days later, however, she was able to provide episodes where she had previously not been able. In addition, episodes that were produced only in very general terms during the attack, were elaborated in much more detail two days later. The same was true seven weeks later. Some examples will illustrate this: 1) Asked to describe an incident occurring while at primary school (age 5-11 years). During TGA attack: "I can't think of anything, nothing exciting happened, I don't recall any trips. I remember one of our teachers went away for a year." Two days later: "I remember being taken to a local canning factory, they showed us the vegetables being cleaned and the process involved. We had to do essays on it. We went on a bus, the head teacher took us and the boys rushed to the back." Seven weeks later: "We went to a local canning factory. We had to write essays about it. We went by coach. They took us all around and explained things. They were doing strawberries at the time. The whole class went and our head teacher took us." 2) Asked about a holiday taken within the last five years During TGA attack: "We all went in a chalet, but I can't remember where. I think it was last September, but I can't really remember. We just all enjoyed ourselves, my son went fishing, we just had fun." Two days later: describing the same holiday: "We had a chalet near Weymouth last September. I remember one day getting up early and going out for a walk with my son to see what birds we could see. We were out before breakfast. We saw blue tits, chaffinches, long tailed tits and we also saw a heron in a pond." Seven weeks later: describing another holiday, "We went to the lakes last February. The scenery around was really pretty, there was snow on some of the mountains and the lakes were icy. We stayed in a friend's hotel and I remember we went over one night to play a board game and we were in teams of three."

b) Famous Faces and Events

Performance on the Famous Faces Test was within normal limits during TGA for all decades, although when reassessed seven weeks later there was a mild $(10 \%)$ improvement in naming with most improvement being for faces from the 1970s and 1980s, suggesting the presence of a modest temporal gradient. Performance on identifying famous events was as good during TGA as afterwards, although the tendency to produce more false positive responses during TGA may obscure a mild impairment. Dating of events was poorer during TGA $(21.3 \%$ overall increase in performance), with the 
greatest improvement being for the most recent events.

\section{Discussion}

The brevity of TGA attacks makes the opportunity to test patients during such attacks rare. However, as this case illustrates, such patients present a valuable opportunity to examine amnesia in patients who act as their own controls. The patient demonstrated the dense anterograde amnesia characteristic of TGA. She showed an impairment in retrograde memory, characterised by a striking difficulty in recalling autobiographical episodes and a more modest impairment in her ability to recall personal or general semantic information, primarily confined to more recent information.

Work on the fractionation of retrograde memory is much more limited than that which has addressed dissociations in anterograde memory, but increasing sophistication in assessment is leading to the conclusion that retrograde memory is at least as complex in the way it breaks down as anterograde memory. ${ }^{2021}$ Arguably, this case supports the notion of a dissociation between episodic and semantic components of retrograde memory. Kopelman et al found that in amnesic patients autobiographical incidents generally correlated with personal semantic information on the AMI, a finding they suggested casts doubt on the usefulness of the episodic/ semantic distinction in amnesia. Nevertheless, the lack of a perfect correlation suggests that there were at least some cases who showed a pattern similar to our patient and in the case of our patient the subsequent recovery of autobiographical memories lends stronger support to the hypothesis that there was a specific impairment in episodic memory.

However, there are a number of caveats which preclude the drawing of firm conclusions. Firstly, there was some impairment in semantic memory. However, this was limited to more recent time periods and if semantic memory is conceptualised as an accumulation of separate episodes (or the mental rehearsal of episodes), ${ }^{14}$ then this pattern would be expected; the patient has to draw more heavily on episodic information to answer questions about more recent aspects of her life. A second caveat is the possibility that differences in scores on the episodic and semantic components of the AMI reflect differential sensitivities of the different sections of the test. This remains a possibility, as does a third caveat which is that the patient may have had an impairment in visual imagery, which, it is argued, ${ }^{22}$ can result in a specific impairment of autobiographical memory. Although informally there was no indication of this, imagery was not formally tested during the attack.

Regarding the aetiology of TGA, there is now compelling evidence that cerebral ischaemia of the thrombo-embolic type does not play a role, at least in the majority of cases. $^{323}$ Migraine, however, is positively associated with TGA and stressful events of various types may precipitate attacks. ${ }^{323}$ The SPECT scan in this case documented a marked bilateral hypoperfusion of the medial temporal lobes during the attack which had resolved by seven weeks post-attack. This finding is in keeping with two previous reports of SPECT imaging during and after TGA $^{1012}$ in which the authors favoured migraine as the pathogenic factor. This still does not really answer the more fundamental question of whether the perfusion deficit is primary, or merely a secondary result of a fall in cerebral metabolism initiated by factors as yet unknown. One possible unifying hypothesis is that diverse stressful precipitants may trigger a release of an excito-toxic neurotransmitter (such as glutamate) which then temporarily shuts down normal memory function in the medial temporal regions via the mechanism of spreading depression, and this in turn leads to a fall in cerebral perfusion. ${ }^{3}$

1 Bender MB. Single episode of confusion with amnesia. fournal of the Hillside Hospital 1956;5:212-15.

2 Fischer CM, Adams RB. Transient global amnesia. Acta Neurol Scand 1964;40:1-83.

3 Hodges JR. Transient global amnesia: clinical and neuropsychological aspects. London: WB Saunders, 1991.

4 Wilson RS, Koller W, Kelly M. The amnesia of transient global amnesia. $\mathcal{F}$ Clin Neuropsychol 1980;2:259-66.

5 Regard M, Landis T. Transient global amnesia: neuropsychological dysfunction during attack and recovery in two "pure" cases. $₹$ Neurol Neurosurg Psychiatry 1984; 47:668-72.

6 Lorusso GR, Stracciari A. Neuropsychological findings during a transient global amnesia attack and its follow up. Ital $\mathcal{F}$ Neurol Sci 1986;7:45-9.

7 Kritchevsky M, Squire LR, Zouzounis JA. Transient global amnesia: characterisation of anterograde and retrograde amnesia. Neurology 1988;38:213-9.

8 Kritchevsky M, Squire LR. Transient global amnesia: evidence for extensive, temporally graded retrograde amnesia. Neurology 1989;39:213-8.

9 Hodges JR, Ward CD. Observations during Transient Global Amnesia: A behavioural and neuropsychological
study of five cases. Brain 1989;112:595-620.

10 Stillhard G, Landis T, Schiess R, Regard M, Sialer G. Bitemporal hypoperfusion in transient global amnesia: a $99 \mathrm{~m}-\mathrm{Tc}-\mathrm{HM}-\mathrm{PAO}$ SPECT and neuropsychological findings during and after an attack. $\mathcal{F}$ Neurol Neurosurg Psychiatry 1990;53:339-42.

11 Goldenberg G, Podreka I, Pfafflmeyer N, Wessely P, Deecke $\mathrm{L}$. Thalamic ischemia in transient global amnesia: a SPECT study. Neurology 1991;41:1748-52.

12 Tanabe H, Hashikawa TH, Nakagawa $\mathrm{K}$, et al. Memory loss due to transient hypoperfusion in the medial temporal lobes including the hippocampus. Acta Neurol Scand 1991;84:22-7.

13 Cermak LS, O'Conner M. The anterograde and retrograde retrieval ability of a patient with amnesia due to encephalitis. Neuropsychologia 1983;21:213-34.

14 Baddeley AD. What is autobiographical memory? In: Conway MA, Rubin DC, Spinnler $\mathrm{H}$, Wagenaar W, Conway MA, Rubin DC, Spinnler $\mathrm{H}$, Wagenaar W,
eds. Theoretical perspectives on autobiographical memory. eds. Theoretical perspectives on autobiographical ment

15 Kopelman M, Wilson BA, Baddeley AD. The Autobiographical Memory Interview: A new assessment of autobiographical and personal semantic memory in amnesic patients. $f$ Clin Exp Neuropsychol 1989;11: $724-44$

16 Wechsler D. Wechsler Memory Scales-Revised. New York: The Psychological Corporation, 1984.

17 Wilson BA, Cockburn J, Baddeley AD. Rivermead Behavioural Memory Test. Bury St Edmunds: Thames Valley Test Company, 1985.

18 Kopelman M, Wilson BA, Baddeley AD. The Autobiographical Memory Interview. Bury St Edmunds: Thames Valley Test Company, 1990.

19 Nelson H. National Adult Reading Test (NART). Windsor: NFER, 1978.

20 McCarthy R A, Warrington EK. Actors but not scripts: The dissociation of people and events in retrograde amnesia. Neuropsychologia 1992;30:633-44.

21 Hodges JR, McCarthy RA. Autobiographical amnesia resulting from bilateral paramedian thalamic infarction a case study in cognitive neurobiology. Brain [in press]

22 O'Connor M, Butters N, Miliotis P. Eslinger P, Cermack LS. The The dissociation of anterograde and retrograde amnesia in a patient with herpes encephalitis. $\mathcal{F}$ Clin Exp Psychol 1992;14:159-78.

23 Hodges JR, Warlow CP. Syndromes of transient global amnesia: Towards a classification: A study of 153 cases. f Neurol Neurosurg Psychiatry 1990;53:834-43. 